\title{
A experiência estadunidense das ações afirmativas: uma análise à luz da teoria da igualdade de Ronald Dworkin
}

\author{
Wilma de Nazaré Baía Coelho*
}

\section{Resumo}

A teoria da igualdade de Ronald Dworkin se baseia no primado da igualdade de recursos, como faceta da justiça distributiva, compatível com uma sociedade liberal fraterna, baseada em um princípio político da igual consideração de todos seus membros. Nesse sentido, o artigo visa a interpretar algumas decisóes da Suprema Corte dos EUA sob a luz da teoria de Dworkin, assim como tecer breves comentários acerca das mais recentes decisões do referido Tribunal sobre as políticas de açôes afirmativas. Por fim, algumas considerações serão tecidas acerca de uma possível aplicação da teoria da igualdade liberal de Dworkin em nosso país.

Palavras-chave: Dworkin, Ronald. Ensino Superior. Igualdade.

* Doutora em Educaçáo pela Universidade Federal do Rio Grande do Norte (UFRN). Professora da Universidade Federal do Pará (UFPA) e da Universidade da Amazônia (Unama). Coordenadora do Núcleo de Estudos e Pesquisa sobre Formação de Professores e Relações Étnico-Raciais (GERA) Coordenadora do Curso de Especialização em Relaçôes Raciais para o Ensino Fundamental/2010-2011. 


\section{Introdução}

O filósofo estadunidense Ronald Dworkin concentra-se em estabelecer as premissas de uma teoria da igualdade em consonância com postulados liberais dentro de um contexto de justiça distributiva, ou seja: sem descurar dos mais caros preceitos liberais, o autor os interpreta a fim de acomodá-los às premissas da justiça distributiva por ele defendidas. Ao adotar por base essas suposições, percebemos em Dworkin a razão pela qual ele lança mão do princípio da igualdade de recursos como paradigma de sua tese. De acordo com esta, a igualdade será garantida na medida em que os recursos sejam distribuídos de forma igualitária, sem que haja dependência de critérios subjetivos de bem-estar. Todavia, essa divisáo leva alguns aspectos em consideração, como, por exemplo: os talentos das pessoas, riscos, escolhas e acasos presentes na vida real.

Em sua teoria, desenvolve razōes político-filosóficas que fundamentam a adoção de critérios de açóes afirmativas, assim como defende sua eficiência como padrão corretor de injustiças sociais. Portanto, em relação à sistemática de uma teoria da justiça distributiva, Dworkin defende a adoção de açóes afirmativas e examina as decisóes mais importantes da Suprema Corte estadunidense sobre o tema, com a finalidade de apontar os erros argumentativos presentes nas referidas decisóes.

O presente artigo, por sua vez, intenciona resenhar a teoria de Dworkin acerca da igualdade, assim como compilar os principais argumentos do autor em favor das açóes afirmativas e esboçar o atual estágio das discussóes sobre o tema nos Estados Unidos da América.

Por fim, será traçado um pequeno esboço sobre a aplicação dessa teoria em nosso país, acentuando a situação educacional brasileira e consideraçôes acerca do posicionamento do Supremo Tribunal Federal em relação à questáo.

\section{A teoria da igualdade de Dworkin}

\section{Igualdade de bem-estar}

Dworkin (2005) considera a igualdade como um ideal político, portanto, pondera qual seria a forma de igualdade decisivamente importante, 
ou seja, a teoria da igualdade, dentre aquelas discutidas pelos liberais, que melhor se adequaria como ideal político a ser adotado por um governo.

Com base nessa premissa, o autor leva em consideração as teorias da igualdade em sua faceta distributiva, quais sejam: a igualdade de bem-estar e a igualdade de recursos. De acordo com a primeira teoria, as pessoas são tratadas como iguais quando se distribuem ou se transferem recursos entre elas até que nenhuma transferência adicional possa deixá-las mais iguais em bem-estar. Já a última afirma que as pessoas são tratadas como iguais quando se distribuem ou se transferem recursos de modo que nenhuma transferência adicional possa deixar mais iguais suas parcelas totais de recursos (DWORKIN, 2005).

Dworkin indaga (e reconhece) que essas são teorias por demais abstratas, mas as minudencia para que possa apontar qual delas deve ser escolhida como ponto de partida de sua teoria acerca da igualdade.

Nesse sentido, refuta a igualdade de bem-estar como ideário político a ser adotado por um governo. Com efeito, aponta que o conceito de bemestar foi inventado pelos economistas para definir o que é fundamental à vida, e não simplesmente instrumental a ela; portanto, para a igualdade de bem-estar, os recursos são valiosos na medida em que atribuem algum bem-estar ao indivíduo. De acordo com esse ideário político, para tornar as pessoas iguais devem-se tornar suas vidas igualmente desejáveis para elas ou oferecer meios para fazê-lo, e não apenas igualar seus saldos bancários (DWORKIN, 2005).

Em seguida, a fim de delimitar as concepçóes de igualdade de bem-estar, com o fito de perquirir qual delas é a que melhor representa este aspecto da igualdade, o autor aponta para a existência de dois grupos principais de teorias acerca do bem-estar, quais sejam:

- teorias bem-sucedidas de bem-estar; e

$\checkmark$ teorias de estado de consciência.

Nessa primeira concepção, há de se realizar a transferência de recursos até que nenhuma transferência adicional possa reduzir as diferenças de êxito, sejam elas preferências políticas, sejam impessoais ou pessoais (DWORKIN, 2005). Todavia, como as pessoas possuem preferências diferentes, diversa será a concepção de igualdade de acordo com o êxito pessoal. De acordo 
com a segunda, a igualdade deve ser alcançada em um determinado nível da vida consciente da pessoa.

Embora se tomem em relevo apenas as preferências impessoais (que importam na satisfação de todas as preferências não políticas), estas se afiguram inviáveis como um indexador de igualdade, pois o governo precisaria tornar as pessoas iguais, ainda que não leve em consideração a realização das preferências impessoais de seus cidadãos. Por outro lado, caso se considerem as preferências pessoais, outros obstáculos intransponíveis se impóem. Para que a igualdade de bem-estar de acordo com o êxito relativo prospere, é necessário que a população inteira informe ao governo acerca de sua situação; ademais, será necessário considerar como importante o que cada pessoa traça para si como ideário e perspectiva de vida. Dessa forma, o êxito relativo será o nível ou o grau de satisfação dessas metas traçadas, levando em consideração o fator sorte, porquanto a igualdade de bem-estar iguala a todos naquilo que todos valorizam do mesmo modo e fundamentalmente. Igualmente, pode-se considerar o êxito total, que seria a avaliação feita por toda uma vida e não apenas de algumas metas alcançadas, ou seja, é um juízo especial que o indivíduo faz da sua vida como um todo. Como todos os demais juízos feitos para se aferir a igualdade de bem-estar, aqueles acerca da própria vida varia de pessoa para pessoa, sendo impossível chegar a um consenso acerca de quais seriam as políticas adequadas a assegurar a igualdade de bem-estar dos indivíduos (DWORKIN, 2005).

Outra deficiência que o autor aponta na teoria da igualdade de bemestar se refere às particularidades que impossibilitam seu êxito. Por exemplo, salienta o caso da satisfação do bem-estar de um portador de deficiências físicas, que, em função da generalidade apregoada pelas concepçóes desta teoria da igualdade baseadas no êxito e em preferências pessoais aplicadas ao caso concreto, poderia receber mais recursos apenas por essa característica. $\mathrm{O}$ que poderia sugerir a possibilidade de se criarem controvérsias quanto à utilidade das verbas repassadas ao enfermo, caso se leve uma consideraçáo subjetiva de êxito total para que se alcance uma igualdade de bem-estar, porquanto ele pode entender que poderia levar uma vida melhor se lhe fosse atribuído um violino, no lugar de uma cadeira de rodas.

\section{A igualdade de recursos}

Após descartar a igualdade de bem-estar, o autor passa a buscar a definição de uma concepção adequada de igualdade de recursos. Dworkin 
(2005) parte do pressuposto de que deve existir a igualdade de qualquer recurso que os indivíduos possuam privadamente, bem como que aquele que interfere na gestấo do dinheiro público é mais rico, e a teoria deve levar em consideração esses aspectos. Portanto, pergunta: qual modelo de propriedade privada constitui uma divisão igualitária dos recursos privados? Para responder a essa pergunta, o autor, baseado em premissas políticas liberais, propóe um modelo de mercado que leva em conta a prosperidade, a eficiência e a utilidade geral. Sustenta que o mercado permite que as pessoas façam suas próprias escolhas. Dessa forma, a atribuição de valores a bens e serviços deve estar no núcleo da teoria da igualdade de recursos.

A fim de exemplificar seu argumento, o filósofo lança mão do exemplo dos náufragos na ilha. ${ }^{1} \mathrm{Na}$ esteira desse exemplo, alguns náufragos estão em uma ilha onde existe abundância de recursos. Nela, todos aceitam dividir tudo igualmente. Mesmo os recursos indivisíveis, após muito esforço, são divididos de forma diferente por meio de lotes, de maneira que ninguém passe a desejar o quinhão de ninguém (ou seja, a divisão tem de passar em um teste da cobiça).

Sustenta, igualmente, a possibilidade de acontecer a troca dos recursos nos lotes; alguns náufragos podem ficar insatisfeitos com ela, por conta dos recursos neles existentes. Destarte, para produzir situaçóes de igualdade, eles estabelecem um leiláo - método de mercado. Conforme salienta Ferraz (2007, p. 248-249):

A escolha do mecanismo do leilão hipotético como mais adequado para alcançar uma distribuição de recursos igualitária no cenário da ilha deserta expressa o lugar fundamental que a liberdade ocupa na concepção da igualdade de Dworkin. O leiláo hipotético, que nada mais é que o mercado em condiçôes ideais, é o único mecanismo que permite uma distribuição de recursos sensível à diversidade de preferências entre as pessoas e às escolhas que essa diversidade implica. Também é um mecanismo que garante que as pessoas arquem com o custo justo de suas escolhas, medido de acordo com a importância que o bem escolhido tem para as demais pessoas participantes do leiláo (o "custo de oportunidade" dos economistas) - o que, como vimos no caso dos "gostos dispendiosos", a teoria rival da igualdade de bem-estar não leva em consideração. 
De acordo com as regras desse leilão, far-se-á a distribuição de mariscos em quantidades iguais para todos (como fichas), e os objetos seráo numerados por lote. Posteriormente, serão atribuídos valores aos lotes. Por meio desses mecanismos, o teste da cobiça é superado, porque ninguém deseja o lote de ninguém, porquanto todos tiveram iguais oportunidades de comprá-los, ajustando seus lances àquilo que lhes interessa. Todavia, poderia haver descontentamento quanto aos recursos encontrados, porém isso seria irrelevante na medida em que seria levado em conta o fator sorte, sendo impossível negar-se a igualdade na divisão feita por meio do leilão.

É importante ressaltar que, caso o leilăo fosse baseado na igualdade de bem-estar, os fatores sorte, gostos particulares e descontentamento dos envolvidos seriam levados em consideração no rateio final, porque, nessa perspectiva, as pessoas escolhem qual tipo de vida querem levar para si, sem contar com as questóes peculiares das outras pessoas. Já na igualdade de recursos, em função da lógica de mercado adotada para o leiláo, as pessoas decidem acerca da vida que querem levar munidas de informaçóes sobre o custo de vida real das escolhas em relaçáo aos outros e ao estoque total de recursos que pode ser utilizado por elas. De acordo com essa faceta da igualdade, as questôes subjetivas, referentes aos gostos e às contingências pessoais, não são levadas em consideração. Todavia, levam-se em consideração as inclinaçóes particulares de como sua vida deve ser encarada, baseada na suposiçāo de igualdade de informaçóes ao entrar no mercado. Ao passo que, na igualdade de bem-estar, caso as pessoas recebessem recursos diferentes em função de seus gostos, sempre criariam situaçôes de desigualdade, o que não acontece na igualdade de recursos, embora as pessoas tenham gostos diferentes e/ou dispendiosos.

Ainda que desconsidere as implicaçôes do mundo real, o autor compreende que alguns fatores sáo importantes no modelo que propóe. Nesse sentido, explica que, com o passar do tempo, a posição inicial do leilão tende a se alterar, pois uns querem mais que outros, porque se dedicam às atividades de forma diferente; uns trabalham em atividades menos rentáveis, gastam mais e passam a cobiçar as partes dos outros (DWORKIN, 2005).

Para tanto, o autor passa a considerar a vida dos náufragos após o leilão. Por considerar o aspecto sorte como preponderante nos resultados obtidos, Dworkin (2005) a divide em: sorte por opção, em que os riscos são calculados e tomados por opçáo, portanto, o indivíduo aceita o risco, e a sorte bruta, tida 
como o resultado de riscos não calculados de apostas não deliberadas. Dentro desse contexto, surge o seguro ${ }^{2}$ como elo entre a sorte bruta e a por opção, uma vez que a escolha de entrar em um seguro é uma aposta calculada.

Em seguida, o autor questiona se é compatível com a igualdade de recursos a existência de pessoas com diferenças em sua renda por conta de divergências na sorte por opção. Para responder a essa questão, expóe que o papel da sorte por opçáo é de determinar que as pessoas devam pagar pelo preço da vida que escolheram seguir, pois aqueles que evitam apostar têm menos do que aqueles que se jogam às apostas. Considera que essas são diferenças autorizadas pelo postulado da igualdade. Porém, há de se considerar que todos tenham a mesma oportunidade de apostas. Ademais, existem escolhas que se fazem na vida, investimentos que podem, em princípio, parecer inócuos ou que sejam dispendiosos, mas que no final das contas dão retorno. Estas, explica Dworkin (2005), são questões que escapam ao problema da igualdade. Com base nesse fundamento, as deficiências físicas não seriam problema para esse caso, pois, se todas as pessoas sabem do risco que correm e da possibilidade de contratar um seguro, suas possíveis deficiências não seriam desigualdades.

Como o próprio Dworkin (2002b) sintetiza para a igualdade de recursos, cabe determinar quais arranjos econômicos demonstram preocupação igual por todos, e devemos fazer isso por meio da quantidade de recursos capazes de produzir o bem-estar dos cidadáos, e não medindo, de forma direta, seu bem-estar de forma individualizada. Contudo, esta proposta náo elimina o risco e a sorte inerentes em uma sociedade real; por essa razão, o autor lança mão da estratégia do seguro para que haja a compensação em casos de infortúnio.

Para que haja efetiva igualdade de recursos, Dworkin (2005) afirma que é necessário que haja a divisão dos recursos em outro momento após o leilão e a contratação do seguro. Nesse passo, e levando em consideração que as pessoas são desiguais em talentos, deve-se neutralizá-lo por meio de redistribuição periódica da renda. O filósofo sustenta que essa hipótese é plausível, porque deixa livre a escolha do modo de vida e dos gastos feitos por cada pessoa, sem que esta seja descurada da igualdade de recursos, uma vez que a renda total será redistribuída. 


\section{O papel da liberdade}

O autor considera liberdade como a liberdade de restriçóes legais. Salienta que sua preocupação não é com a liberdade em geral, mas sim com a liberdade em relaçáo direta com a igualdade de recursos (DWORKIN, 2005). Nesse aspecto, defende o argumento liberal de que se deve evitar uma grande ingerência na liberdade individual, porém, em alguns momentos, a liberdade deve ser restringida em detrimento da igualdade de recursos. Se a igualdade de recursos é a melhor teoria, a liberdade torna-se parte dela e a ela não se opóe. $\mathrm{O}$ autor afirma que a liberdade (que não pode ser considerada como um valor metafísico bastante em si mesmo) no âmbito liberal pode ser restringida por conta de determinados valores; estes poderiam ser, por exemplo, os relativos à igualdade distributiva.

As liberdades, portanto, devem ser defendidas de acordo com a melhor definição da igualdade distributiva. Dessa forma, na igualdade de bem-estar, como a preocupação é com a satisfação de gostos e preferências, pairam dúvidas, a partir dessa perspectiva da igualdade, acerca da possibilidade de assegurar um mínimo das liberdades morais importantes, uma vez que as pessoas poderiam estar dispostas a sacrificá-las em busca da própria satisfação pessoal.

Como a igualdade de recursos está baseada em escolhas que repercutem em vários aspectos da vida do indivíduo - ou seja, a vida que vai levar, as escolhas que faz com seus recursos disponíveis -, a fim de que este ideário vingue, é necessário que a estas pessoas sejam garantidas determinadas liberdades. A liberdade, por conseguinte, é necessária à igualdade (DWORKIN, 2005).

De início, Dworkin apresenta duas concepçóes de liberdade. A liberdade em sentido simples, entendida como ausência de restriçóes, e em sentido normativo, como a ideia de como as pessoas deveriam ser livres, ou seja, aspectos que as pessoas devem considerar para serem livres. Para o autor, a liberdade tem caráter e sentido relacionais, pois varia de acordo com o sentido que tem para cada indivíduo, não como um valor autônomo e bastante em si mesmo.

Sentencia que a liberdade é uma faceta do conteúdo da igualdade distributiva, portanto, ainda que se restrinjam alguns direitos, desde que se alcance a igualdade, a liberdade será garantida, e as escolhas no leilão hipotético só serão feitas de forma isenta e efetiva se os indivíduos forem realmente livres, como sintetiza Ferraz (2007, p. 244-245): 
Essa corrente [do igualitarismo liberal, tal qual defendida por Dworkin] aceita a premissa liberal de que a distribuição das riquezas sociais deve expressar de algum modo as escolhas das pessoas e que, portanto, uma distribuição idêntica de riquezas não é necessariamente uma distribuição justa ou igualitária. Em direção oposta, porém, deve-se concluir que as desigualdades materiais que não podem ser atribuídas às escolhas das pessoas, ou seja, as que se devem a circunstâncias fora de seu controle, não são justificadas. Trata-se da aplicação, no campo da justiça distributiva, do princípio ético bem estabelecido da responsabilidade.

\section{A igualdade de recursos e o liberalismo: aspectos morais da comunidade liberal}

A análise da igualdade de recursos perpassa, na perspectiva do autor, pela adoção de um modelo político que possa ser coerente com suas premissas. Nesse sentido, considera que o liberalismo político é o modelo mais adequado para a aplicação da igualdade de recursos e para a interpretação de uma comunidade liberal (DWORKIN, 2005). Com efeito, a tolerância liberal é importante no que diz respeito à determinaçáo do reflexo determinado pelo bem-estar da vida de um indivíduo e seu impacto na sociedade como um todo. Todavia, a comunidade política não é idêntica ao cidadão, mas o precede.

Para que haja a escorreita observância dos princípios éticos, devem ser ponderadas as questóes relacionadas ao controle do ambiente ético. Este não deve ser realizado apenas pela maioria. $\mathrm{O}$ ambiente ético deve determinar que as pessoas exerçam, de forma individual, o mesmo impacto que as outras, de acordo com uma igualitária participação nos recursos. Nesse sentido, parte-se da suposição de que o ambiente econômico e o ético fazem parte de um mesmo ambiente. Dessa forma, algumas legislaçóes moralistas podem limitar o uso da propriedade e o modo de usá-la, repercutindo, portanto, na economia (DWORKIN, 2005). Supóe-se que a maioria não pode determinar como cada um levará sua vida, pois essas decisões, como são tomadas individualmente, representam a tolerância liberal em questóes 
éticas. Esse argumento exclui a premissa de que o ambiente ético deve ser determinado em termos de tudo ou nada pela maioria.

De acordo com suas consideraçóes, a comunidade é representada pela atuação de agentes que fazem parte de sua estrutura, sendo impossível entender aquela por meio somente destes. Dworkin (2005) conclui que determinada questão, do aspecto prático, deve ser potencialmente generalizável a ponto de poder ser considerada como emanada da sociedade, como as leis e as decisões políticas.

A liberdade, a igualdade e a comunidade devem ser encaradas, portanto, de acordo com o que preceitua o autor com fundamento no liberalismo, ou seja: uma igualdade como a de recursos; liberdade com limite no direito dos outros e uma comunidade que respeita as particularidades individuais (DWORKIN, 2005).

Por fim, como a justiça é um parâmetro ético, devemos nos guiar pela sua melhor teoria, e esta é a da igualdade de recursos. Dessa forma, a tolerância liberal impede que se utilize a lei para estabelecer padróes éticos de como se deve viver bem de acordo com uma maioria (DWORKIN, 2005).

No final de suas discussóes acerca da teoria da igualdade, o autor discorre sobre o acaso e a escolha. Nesse sentido, expóe sua face de liberal igualitário ao salientar questóes relativas à responsabilidade consequencial, ou seja, até que ponto se determina se uma pessoa pode ter responsabilidade por alguns aspectos de sua vida e, mesmo, até que ponto a comunidade deve agir para aliviar essas desvantagens (DWORKIN, 2005). O autor pondera que algumas contingências são decorrentes de escolha. Nesses casos, não haveria direito a recompensas. Porém, existem algumas críticas a esse pensamento, em especial no pertinente a algumas escolhas deliberadas decorrentes de situações que fogem ao controle do agente. As escolhas dependem de valores éticos e morais que são adquiridos pela pessoa e tomam forma por meio das conclusóes extraídas da experiência de vida, daí a importância dos juízos de valor feitos pelo indivíduo. A forma como são encarados alguns gostos é permeada por um entrelaçado de juízos de valor feitos pela pessoa.

Após tratar das escolhas, Dworkin (2005) tenta rebater algumas críticas relacionadas à sorte e à igualdade de recursos. Sustenta que uma enfermidade, por exemplo, é algo que independe da escolha, é um acaso, e, portanto, a falta de recursos para sua resolução enseja a compensação 
desse infortúnio como parte desse ideal teórico-político. No caso da dor, a pessoa poderia fazer um seguro que lhe garantisse a compra de remédios caros para que possa aplacar seu problema. Porém, essas realizaçóes devem ser possibilitadas por meio de recursos igualmente distribuídos, isso sem considerar valores objetivos de bem-estar, apenas permitindo, pelos recursos, que a pessoa faça a escolha que lhe aprouver.

\section{As ações afirmativas na experiência estadunidense: uma abordagem dos principais julgamentos a partir da teoria da igualdade de Dworkin}

\section{Regents of the University of California vs. Allan Bakke (1978)}

Um dos casos mais emblemáticos envolvendo a política de açóes afirmativas é o caso que ficou conhecido como Bakke. No presente caso, a Faculdade de Medicina da Universidade da Califórnia, situada em Davis, elaborou um programa de ação afirmativa (chamado "programa de forçatarefa"), em que eram ofertadas 16 vagas para aqueles com dificuldades educacionais e econômicas, em especial para estudantes negros e de outras minorias. Os candidatos que se inscreviam para as vagas das minorias, ainda assim, passavam pelo mesmo processo que os demais, contudo, não necessitavam alcançar os mesmos pontos médios que os outros. Todavia, esses candidatos eram submetidos a um rigoroso processo de qualificaçáo de requisitos especiais.

Allan Bakke era branco e se candidatou para as 84 vagas restantes oferecidas pela faculdade. $\mathrm{O}$ aluno não foi aceito, porém possuía notas altas o suficiente para ingressar na universidade, caso não houvesse as vagas destinadas às minorias. Em função dessa situação, recorreu ao Tribunal da Califórnia, que lhe concedeu o direito de se matricular, mas a instituição buscou a Corte Suprema para tentar reverter tal decisão.

A decisão da Corte Suprema foi dada por uma maioria apertada em favor do pleiteante, na medida em quem teve seu direito de ser matriculado na universidade garantido, mas a questão acerca da constitucionalidade dos programas de açóes afirmativas não foi plenamente debatida, uma vez que alguns juízes sequer adentraram na questão constitucional, enquanto outros, 
como Powell, construíram argumentos dúbios e evasivos, conforme se verá adiante (DWORKIN, 2000).

Os advogados de Bakke argumentaram que os programas de ação afirmativa eram inconstitucionais porque violariam os direitos individuais daqueles que não obteriam as vagas na universidade. A fim de refutar esse argumento, o autor estadunidense, em um primeiro momento, se questiona qual seria esse direito. Pode ser o de ser avaliado de acordo com seu mérito, ou seja, apenas como indivíduo. Dworkin (2000) pondera que essas argumentaçóes apenas demonstram o princípio de que ninguém pode ser prejudicado pelas açôes de terceiros, mas essa é uma conclusão aparente, na medida em que estavam em oposição um objetivo social desejável e direitos individuais importantes que pudessem se anular mutuamente.

Dando continuidade à sua explanação, o filósofo aponta o caso de alunos apenas avaliados pelo mérito. Nesses casos, pondera, apenas seriam levadas em consideração as notas em um teste de inteligência (o autor lembra que a utilização isolada desse método é contestada pelas escolas de Medicina), o que demonstra que, se ela escolhe seus candidatos visando a formar os médicos que considera úteis, tudo dependerá dos fatores que os tornarão úteis. A escola de Davis, por exemplo, atribui aos candidatos regulares uma nota de referência de nível (o "benchmark score"). Essa nota refletia vários fatores: chances dos candidatos de atuar como médico eficiente, teste de aptidão e histórico escolar. Portanto, arremata Dworkin (2000), em dadas situaçóes, ter uma pele negra é um mérito, na medida em que torna determinada pessoa um médico mais útil à sociedade, mas não que uma raça seja inerentemente superior a outra.

Em seguida, refuta o argumento levantado por Bakke de que deveria ser julgado como indivíduo e não como membro de um grupo. Dworkin (2000) argumenta que os testes aplicados levavam em consideração um ponto de corte; quem não os alcançava, era considerado reprovado, embora possuísse inúmeras qualidades que pudessem ser úteis a um médico. Nessa medida, consideram-se, irremediavelmente, esses candidatos como participantes de um grupo, pois a faculdade toma como parâmetro de conveniência um suposto nível médio de inteligência que seria um indício de capacidade médica; ora, isso é válido estatisticamente, mas não para os indivíduos, uma vez que suas qualidades pessoais não são levadas em consideração e podem ser superiores às daqueles que obtiveram maiores notas. 
Ademais, o autor salienta que Bakke foi recusado por outra universidade de Medicina porque tinha 33 anos (DWORKIN, 2000). A instituição que o rejeitou considerou que ele poderia contribuir muito pouco para os serviços médicos, diferentemente de um jovem que ingressa na faculdade com uma idade inferior. De acordo com o autor, não houve uma profunda investigação acerca das aptidóes pessoais do candidato, apenas a utilização de uma regra empírica. Ou seja, nesse caso e no do parágrafo acima, Bakke foi julgado como participante de um grupo.

Conclui o autor explicando que a escola permitiu que brancos se inscrevessem nas 16 vagas destinadas àqueles com desvantagens econômicas ou educacionais, mas tomara a decisão administrativa de que nenhum branco seria aceito, justamente em função da finalidade daquelas vagas. $\mathrm{O}$ autor supõe que essa decisão, de acordo com uma possível teoria administrativa, explicita que o médico branco, nessas condiçôes, não teria o mesmo sucesso que um médico negro bem treinado para compensar as desigualdades sociais. E conclui que esse argumento é mais plausível que os anteriores, e se aqueles não violaram direitos individuais, esse último também não (DWORKIN, 2000).

Bakke sustentou, igualmente, a igualdade racial como impossibilidade de fator discriminante para sua admissão. Dworkin (2000), prontamente, aponta a falha nesse argumento: o direito constitucionalmente assegurado de igualdade dos negros foi violado sistematicamente. A discriminação racial advém de um processo histórico baseado em um insulto, pois gerada pelo desprezo a uma raça supostamente inferior. Ademais, algumas características físicas e psíquicas independem da escolha, porquanto ninguém escolhe ser negro ou escolhe ter menos aptidão intelectual, bem como não escolhe ser mais velho ou não talentoso para o basquete. Por fim, a reivindicação de Bakke é ridícula, porque sua raça não sofre discriminação e desprezo. No caso, ele não foi aceito por conta de um cálculo racional do uso socialmente mais benéfico dos recursos limitados da educação médica, uma vez que a justiça racial é uma medida social urgente e necessária na atualidade.

No mesmo caso, importantes consideraçóes foram feitas a respeito do futuro das açóes afirmativas nos Estados Unidos, em especial aquelas contidas no voto do juiz Powell. Para o referido juiz, além da estrutura, uma política de açóes afirmativas que pode ser considerada como constitucional tem de ter um propósito (2000). Na linha do voto de Powell, existem diferenças nos 
planos que envolvem cotas para minorias e aqueles programas mais flexíveis, que tomam a raça apenas como um fator a ser levado em consideração nas admissóes.

O juiz da Suprema Corte salientou a necessidade de discussão das classificaçôes raciais utilizadas, em especial das decisôes políticas de algumas instituições de determinar critérios de discriminação por conta de algumas particularidades dos indivíduos. Caso o tribunal se ocupasse desses critérios, estaria entrando em uma seara que diz respeito aos critérios de avaliação de um processo democrático. Nesse ponto, lembra a doutrina das classificaçóes suspeitas, testadas por meio de uma "investigação rigorosa" (DWORKIN, 2000, p. 464). Sustenta que, para que seja constitucional essa classificação racial, é necessário que haja um interesse governamental compulsório e a demonstração de que o uso dessa classificação não é irracional, mas necessário, uma vez que as classificaçôes raciais que póem um grupo como minoria são consideradas suspeitas. Powell sustentou que a classificação benigna se submete ao mesmo crivo que coloca em desvantagem uma minoria e que, portanto, sendo suspeita, deveria entrar em um padrão de rigorismo a impor um interesse compulsório do governo.

\section{DeFunis vs. Odegaard (1974)}

Em outro caso importante acerca do tema, julgado em 1974, a Suprema Corte analisou o processo de DeFunis, originado pelo fato de a Universidade de Washington não o ter aceitado como aluno, ainda que, por ter notas altas, pudesse ter entrado na instituição caso fosse participante de algum grupo minoritário (DWORKIN, 2002a). O caso chega à Corte Suprema sob a alegação de violação do direito à igual proteção, previsto na $14^{\mathrm{a}}$ emenda à Constituiçáo dos Estados Unidos. No intuito de contrapor os diferentes tipos de direito abarcados pela $14^{\mathrm{a}}$ emenda, o autor lembra o caso Sweatt (1950), em que um negro tentou ingressar na Faculdade de Direito da Universidade do Texas, mas foi recusado porque uma lei determinava que somente brancos podiam frequentar a faculdade, caso admitidos. A Suprema Corte declarou que a lei, nesse último caso, violava os direitos do autor garantidos na $14^{\mathrm{a}}$ emenda.

Esses casos, afirma Dworkin (2002a), póem em discussão as premissas liberais acerca das açóes afirmativas, na medida em que elas não estariam mais servindo a seus propósitos. Nesse passo, o autor visa a refutar a afirmação 
de que distinções com base na raça são inerentemente injustas, uma vez que violam os direitos de membros individuais de grupos não igualmente favorecidos.

O filósofo distingue o direito a igual tratamento (direito a igual distribuição de alguma oportunidade, recurso ou encargo) e o direito a tratamento como igual (direito de ser tratado com o mesmo respeito e consideraçáo de qualquer outra pessoa), no intuito de demonstrar que DeFunis não tem direito a igual tratamento na alocação de vagas na Faculdade de Direito, mas tem direito de que seus interesses sejam examinados com a mesma simpatia e tão plenamente quanto os interesses de quaisquer outras pessoas, inexistindo bases para a afirmação de que a $14^{\underline{a}}$ emenda torna ilegais todas as classificaçóes raciais (DWORKIN, 2002a).

Dworkin (2002a) argumenta que qualquer política segregacionista em relação aos negros será injusta, na medida em que estes foram vítimas do racismo histórico, da escravidão e de inúmeras práticas odiosas. E esse preconceito está, intrinsecamente, baseado no insulto. Em consequência, ainda que em princípio possam parecer nobres, quaisquer políticas que visem a discriminar os negros serão injustas em funçáo da história de preconceito racial de que estes são vítimas. ${ }^{3}$

No entanto, para determinar quando uma sociedade está melhor, o autor lança mão do sentido utilitarista (quando o nível de bem-estar de todos é alcançado) e do sentido ideal (está melhor porque é mais justo ou mais próximo de uma sociedade ideal, quer o bem-estar médio seja ou não aumentado). Por meio desses conceitos, encontramos uma diferença sensível entre os casos Sweatt e DeFunis, porquanto a universidade do Texas não poderia alegar que a segregação torna a sociedade mais justa (DWORKIN, 2002a).

Dessa forma, os argumentos que se utilizam para justificar a segregação devem ser utilitaristas, porém, esses se deparam com inúmeras dificuldades, conforme visto anteriormente, como, por exemplo: sua impossibilidade de aferição objetiva; a impossibilidade de ser confirmado se essas políticas aumentam ou diminuem de forma efetiva o bem-estar da população, bem como o fato de que tais políticas nunca chegam a alcançar um nível de preferência ideal levando em consideração o bem-estar de cada membro da comunidade (DWORKIN, 2002a). 
Portanto, já se podem demarcar as diferenças entre os casos DeFunis e Sweatt. Os argumentos favoráveis a um programa de admissões que discrimine negativamente os negros são todos argumentos utilitaristas que se baseiam em preferências externas de uma maneira tal que infringem o direito constitucional dos negros de serem tratados como iguais. Os argumentos favoráveis a um programa de admissóes que discrimine em favor dos negros são ao mesmo tempo utilitaristas e de ideal. Alguns argumentos utilitaristas baseiam-se em preferências externas, mas os argumentos de ideal não se baseiam em preferências, mas sim no argumento independente de que uma sociedade mais igualitária será uma sociedade melhor. Esse argumento não nega a ninguém o direito de ser tratado como igual (DWORKIN, 2002a).

\section{O estágio atual das ações afirmativas nos Estados Unidos: breve análise dos casos mais recentes referentes ao Ensino Superior}

Infelizmente, conforme previra Dworkin (2005), a Suprema Corte dos Estados Unidos considerou Bakke como um precedente a ser seguido nas mesmíssimas condiçóes descritas no corpo do texto, conforme pode ser observado no julgamento Grutter vs. Bollinger, 539 U.S. $306(2003)^{4}$, cujo voto principal foi da juíza Sandra Day O'Connor.

Naquela oportunidade, a juíza O'Connor afirmou que ações afirmativas deveriam atender a um interesse governamental compulsório e não deveriam pôr em risco os chamados grupos suspeitos, ou seja, aqueles aos quais são impostas determinadas discriminaçôes. Os programas de ações afirmativas devem almejar, portanto, objetivos bem definidos e que tenham um fundamento explícito e constitucionalmente justo. Pois, conforme salientou o tribunal, seria impossível aferir as reais intenções dessas discriminações, como, por exemplo, corrigir as desigualdades raciais.

A Corte Suprema pôde considerar inconstitucional o programa que outorgava, de maneira automática, pontos para candidatos oriundos de minoria para acesso a vagas na instituição de Ensino Superior, no caso Gratz vs. Bollinger, 539 U.S. $244(2003)^{5}$, porquanto não ficou demonstrado de que modo o programa passava pelo escrutínio estrito de apresentar um interesse compulsório plenamente justificável, pois tal política não serviria 
para aumentar a diversidade do corpo estudantil da universidade, da maneira que Powell considerou no caso Bakke.

Em um mais recente caso, Community Schools vs. Seattle School District no 1, 551 U.S. 701 (2007), a secretária de Educação de Seattle permitira que os estudantes pudessem escolher qualquer escola de Ensino Médio do distrito para matricular-se. Uma vez que alguns alunos escolheram as mesmas escolas, o distrito lançou mão de um sistema para decidir quais alunos seriam admitidos nas escolas populares, quando fosse o caso de empate. O critério de desempate mais importante foi o fator racial, destinado a manter o equilíbrio e a harmonia raciais, baseados na demografia racial da população de Seattle. De acordo com esse sistema adotado, em uma escola particular, brancos ou não brancos poderiam ser favorecidos, dependendo de qual raça seria utilizada para trazer o equilíbrio racial mais próximo da meta demográfica. Não existia qualquer distinção entre as várias categorias de não brancos, asiático-americanos, hispânicos, nativos estadunidenses e afroamericanos; todos foram tratados apenas como "não brancos" para efeitos de desempate.

No referido caso, de acordo com o pronunciamento da Suprema Corte, liderada pelo voto do juiz John Roberts, tal política violava a cláusula da igual proteção e não passava no teste dos interesses compulsórios, uma vez que seus objetivos institucionais não demonstravam, claramente, suas reais justificativas. ${ }^{6}$ Isso quer dizer que a Corte considerou que o equilíbrio racial nas escolas de Seattle não é um interesse governamental compulsório. Ademais, os juízes consideraram que era impossível buscar as reais intençóes das consideraçóes relacionadas à raça - ou seja, se o projeto visava a afetar negativamente os grupos suspeitos ou criar uma situação de vantagem indevida por uma raça -, pois nunca houve histórico de segregaçóes ou de reparaçôes a serem feitas naquela cidade.

\section{Conclusões}

Nesse contexto, cumpre estabelecer alguns pontos de intersecção entre a teoria da igualdade de Dworkin e sua defesa em relação às políticas de açóes afirmativas, em especial aquelas no Ensino Superior em nosso país. Em primeiro lugar, apontamos para a noçáo de comunidade ética que o autor apresenta, considerada como uma unidade de decisóes políticas coletivas que 
podem ser atribuídas aos indivíduos que a constituem, o que quer dizer que a atuação da comunidade deve se pautar em critérios objetivos de justiça e equidade. Portanto, um argumento acerca da justiça das açóes afirmativas deve ser considerado, uma vez que um dos seus fundamentos principais é, justamente, a busca de uma sociedade mais justa, que represente de forma efetiva todos os matizes que a compóem em todas as suas camadas.

A partir desse argumento de princípio e com base em algumas consideraçóes feitas pelo autor, devemos considerar que as vagas no Ensino Superior não representam um direito individual assegurado constitucionalmente, tampouco o é a oferta de ensino de qualidade, o que torna as vagas no Ensino Superior, sem dúvida, um recurso ofertado pela sociedade, porém de escassa disponibilidade.

Náo precisamos ir longe para estabelecer o consenso de que a raça negra sofreu um sistemático processo de discriminação em função de sua cor e de que, em um passado não muito distante, era considerada objeto e suportara, além do aviltamento moral do racismo, a escravidão. Nesse aspecto, podemos considerar que os recursos da sociedade, como um todo, nunca foram repartidos ou desfrutados por esse grupo de forma igualitária. Não caberia, neste breve estudo jurídico, assentar a fraqueza do argumento racista baseado em um discurso de fundamentos biológicos e sociológicos; porém, esse preconceito determinou discriminaçóes na busca de empregos, de status social, dificuldades no ingresso em universidades e de participação política dessas pessoas. Não podemos olvidar que as heranças da escravidão importaram em uma história de pobreza para o grupo referido, uma vez que alguns recursos lhes foram negados em função de sua condição anterior. Esse quadro se reproduz após séculos, de acordo com Ziccarelli Pandolfi (2007), na medida em que se engendra um círculo vicioso de insucesso escolar e exclusão social, porquanto negado o acesso à universidade, mais difícil o acesso aos postos de maior status econômico no mercado de trabalho.

Em outras palavras, nunca houve uma distribuição igualitária dos recursos disponíveis da sociedade para os grupos afrodescendentes. Destarte, a fim de se alcançar uma igualdade de recursos que seja coerente com os princípios morais de uma sociedade democrática, é necessário redistribuir recursos existentes na sociedade para corrigir, de maneira prospectiva, as desigualdades perpetradas pela má distribuição (ou a falta) de recursos. Por recursos, podemos entender os bens materiais, como os monetários 
(na medida em que essas pessoas discriminadas recebem salários menores); educacionais (impossível negar que as piores escolas são aquelas frequentadas por esses grupos discriminados); políticos (a falta de representatividade política para a defesa dos interesses do grupo) e imateriais, tais como: respeito, fraternidade, tratamento como igual, etc.

Com efeito, a falta desses recursos determinou uma estratificação odiosa na sociedade brasileira, segregando os negros em sua efetiva representatividade na comunidade como um todo. Em outras palavras, em comparação com as posiçóes sociais presentes na comunidade (como exemplo: algumas profissóes, posiçóes artísticas, culturais, educacionais e políticas), existe, portanto, um claro descompasso em comparação com o número de indivíduos que compóem esse grupo. Portanto, tomando por base a teoria da igualdade de recursos, as políticas de açóes afirmativas se justificam, pois elas almejam redistribuir os escassos recursos postos à disposição para a Educaçáo Superior.

Complementando o exposto, Brito Filho (2006) considera que os escritos de Dworkin acerca das açóes afirmativas seguem um roteiro demonstrativo de sua utilização e intenta adequar a teoria do filósofo estadunidense à nossa realidade. $\mathrm{O}$ primeiro ponto desse roteiro seria revelar, de acordo com o autor, em que contexto as açóes afirmativas se justificam. Tais ações devem ser encaradas como meio de combate à discriminação. Esse combate, por sua vez, pode ser feito de forma repressora (consubstanciado pela expedição de normas que vedem práticas discriminatórias) ou/e de discriminação positiva (por meio da adoção de disposiçóes que favoreçam a inclusão de determinados grupos alvo de discriminação). $\mathrm{O}$ primeiro modelo é estático e não permite a inclusão daqueles que sofrem a discriminação, não se caracterizando pela oferta de condiçóes de reintegraçáo dos excluídos. Todavia, ressalta que o modelo positivo é uma evolução do modelo repressor, porquanto ambos coexistem, e que o modelo positivo não pode ser considerado de forma isolada.

Após a justificativa, o autor passa a perquirir a recepção do modelo de açóes afirmativas em nosso ordenamento jurídico. No caso do Brasil, Britto Filho busca subsídios na proteção da dignidade da pessoa humana (art. 1º, III da Constituição Federal de 1988) e nos objetivos fundamentais da República, que são: construção de uma sociedade justa, desenvolvimento nacional, erradicação da pobreza e redução das desigualdades sociais, e promoção do bem-estar, sem qualquer discriminação (art. 3ำ da CF/88). Portanto, a adoção de medidas 
positivas de inclusão dos grupos que são alvo de discriminação e preconceito não é uma opção governamental, mas sim uma imposição necessária para a concreção dos objetivos de nossa República.

Apesar de justificada a necessidade de adotar políticas de ações afirmativas, assim como a recepção dessas medidas por nosso ordenamento, um grande problema ainda carece de solução: as condições e os critérios para adoção das referidas políticas, ou seja, sua forma, duração e intensidade. Nesse sentido, Brito Filho (2006) afirma que a eficiência dessas açóes deve ser o primeiro critério a ser observado, na medida em que tais medidas devem ser capazes de reduzir as desigualdades, quando nenhuma outra possibilidade de ação estatal fosse eficaz nesse objetivo. Outro critério é a escolha das políticas, que podem ser tanto de cotas, como, por exemplo, de incentivos fiscais. A escolha da medida pode variar de acordo com o grupo vulnerável envolvido.

Um argumento importante acerca da eficiência das ações afirmativas no Ensino Superior está no fato de que, sozinhas, não darão conta de transformar toda a situação de desigualdade, caso não venham acompanhadas de reformas estruturais na educação. No entanto, até que se contemple uma reforma completa no ensino e se colham os benefícios de seu resultado, atrasaria, consideravelmente, o processo de correção de desigualdades prementes na sociedade. Portanto, o argumento de que as desigualdades se corrigirão com a reforma completa, total e efetiva das condiçóes de ensino é frágil, pois ou se muda tudo ou náo se modifica nada quanto às desigualdades no seio da sociedade, sem consideração quanto ao tempo para a realização de tais mudanças estruturais. ${ }^{7}$

Outro critério importante é o da capacidade de correção da desigualdade, com o alcance dos resultados projetados e o mínimo de impactos negativos. Nesse contexto, o tempo de adoção das medidas e o controle de sua funcionalidade são exemplos importantes desta característica. ${ }^{8}$

Ainda que os argumentos expostos acima sejam capazes de afirmar a constitucionalidade das açóes afirmativas, muitos autores argumentam que o Brasil apresenta suas discriminações raciais disfarçadas sob o manto das diferenças sociais, ou seja, consideram que nosso problema não seria em discriminar a cor, mas as posses. ${ }^{9}$ 
Ademais, uma política, não necessariamente, se iguala em objeto com a outra. As cotas de cunho socioeconômico possuem um objeto mais específico, qual seja, dar possibilidade de igualar os recursos materiais financeiros daqueles que, historicamente, a ele poderiam ter acesso, mas não o obtiveram por circunstâncias alheias à sua vontade, que, consequentemente, os impediram de ter acesso ao Ensino Superior, a fim de perpetrar uma política de erradicação da pobreza, independentemente de consideraçóes sobre raça ou gênero. Portanto, tal política não seria suficiente para tornar a sociedade brasileira mais justa, no sentido de espelhar, com fidelidade, os diferentes matizes que compóem nossa sociedade (o número da população negra e seu consequente reflexo nas posiçóes políticas e sociais), ainda que não contemple apenas aqueles que sejam economicamente hipossuficientes.

Sem dúvida, tal situação de conceituação acerca das açóes afirmativas em nossa constituição tem de levar tal questão em consideração, porquanto a injustiça causada pelo preconceito pode não parecer tão evidente aos olhos de determinados pensadores, ao ponto de considerar que devemos adotar tais políticas no Ensino Superior, mesmo que tenhamos um direito fundamental à não-discriminação assegurado na Constituição.

Com efeito, alguns autores poderiam pensar que devemos sanar, preferencialmente, questóes econômicas, porquanto não seríamos racistas ao ponto de considerar que praticamos a injustiça do preconceito racial e, consequentemente, não seriam necessárias discriminaçóes positivas para tornar a sociedade mais justa. Mesmo Dworkin aponta que devem existir critérios para determinar quando uma política racial de ação afirmativa deve ser utilizada; no entanto, como eles seriam estabelecidos no Brasil? Como visto parágrafos acima, Brito Filho (2006) respondeu tal resposta a contento. ${ }^{10}$

Por fim, a adoção das medidas de ação afirmativa no Ensino Superior não visa a excluir o mérito do indivíduo no ingresso, mas permite combiná-lo com outros critérios de acesso à universidade (um recurso disponível pela sociedade), que possibilitam o acesso de todos os grupos existentes na sociedade de forma justa, pois as entidades de Ensino Superior (especialmente as públicas, subvencionadas por toda a sociedade) existem para o benefício de todos, sendo injusto o monopólio do ingresso em seus quadros de apenas uma parcela dos integrantes da sociedade. 


\section{Notas}

1 Como explica o próprio Dworkin (2002b), o exemplo do leilão e do seguro são situaçóes contrafáticas, utilizadas para determinar que a divisão presente no mundo real seria mais justa se todos tivessem igual oportunidade de se proteger contra uma variedade de riscos e intenciona identificar como poderia se proceder, a fim de se atingir uma distribuição atual justa.

2 O seguro, portanto, surge como o mecanismo de mercado eficaz para determinar a justa distribuição de recursos, bem como visa a resguardar a individualidade e a liberdade do indivíduo, na medida em que este pode escolher em quais apólices investir e de quais riscos se proteger. Ademais, a cobertura que o homem prudente médio contrataria no mercado de seguros hipotéticos contra o risco de possuir menos recursos por conta de circunstâncias involuntárias é a medida correta para redistribuir na sociedade os recursos entre os que ganham e os que perdem no jogo desigual do mercado.

3 No entanto, Dworkin (2005) é expressamente contra quaisquer políticas compensatórias inerentes aos programas de açóes afirmativas, na medida em que seria impossível conceber que uma raça deve compensar a outra. Mas suas intençôes são prospectivas, ou seja, visam a dar a alunos beneficiados a chance de um futuro e oportunidades melhores.

4 O caso surgiu em 1996, quando Barbara Grutter, que era branca, foi rejeitada pela University of Michigan Law School, mesmo tendo obtido notas altas nos exames de admissão. Ela entrou com uma ação alegando que a universidade a havia discriminado com base em critérios raciais, em violação à Décima Quarta Emenda da Constituição dos Estados Unidos e do Título VI do Civil Rights Act de 1964. Ela argumentou que tais critérios davam significativa vantagem a grupos minoritários e excluiu os brancos das universidades, bem como argumentou que a universidade náo tinha nenhum interesse convincente para justificar o uso da raça como critério de admissão dos candidatos das minorias.

5 A Universidade de Michigan usava uma escala de determinados pontos para classificar os candidatos, e estes deveriam alcançar uma referida pontuação necessária para garantir sua admissão. A universidade atribui 
a grupos étnicos, incluindo afroamericanos, hispânicos e nativos estadunidenses, um bônus automático de 20 pontos nessa escala. Jennifer Gratz e Patrick Hamacher, ambos brancos e residentes em Michigan, não foram aceitos na universidade e entraram com uma ação alegando que tiveram violado o seu direito constitucional à igualdade.

6 De acordo com o juiz Roberts; "when the government distributes burdens or benefits on the basis of individual racial classifications, that action is reviewed under strict scrutiny". Uma vez que, "racial classifications are simply too pernicious to permit any but the most exact connection between justification and classification." Portanto, para que passe no teste do escrutínio, "a narrowly tailored plan must be presented in order to achieve a compelling government interest."

7 Não podemos deixar de ressaltar que as justificaçóes para as ações afirmativas em Dworkin não se baseiam em considerações relacionadas ao fim da discriminação racial na sociedade. Elas são seu pressuposto, não o meio de erradicá-la. A prática odiosa do racismo serve de meio para justificar as políticas de açóes afirmativas, visando a criar uma sociedade mais justa, que seja condizente com a realidade de sua composição social. Leis e políticas desta natureza possuem uma função pedagógica secundária. $\mathrm{O}$ objetivo do artigo é, portanto, propugnar pela sua constitucionalidade e necessidade de adoção, ainda que não seja o meio mais efetivo para erradicar o racismo no Brasil. A igualdade oferecida pelas políticas de ação afirmativa não dizem respeito à erradicação do racismo. Pessoas mais instruídas não significam pessoas isentas de preconceitos. As políticas acima não visam a instruir os que praticam o racismo a mudarem de opiniáo, mas propor condiçóes para determinada parcela da sociedade que não obteve uma repartição igualitária de recursos por conta do racismo por ela sofrida.

8 Para uma completa análise do sistema de cotas implantado pela Universidade Federal do Pará, ressaltando seus aspectos positivos e negativos, e cotejando as diretrizes propostas pela Resolução n. 3.361, de 5 de agosto de 2005, do Consepe com os critérios de justificação e efetividades propostos, conforme visto acima, pelo autor, com base nas teses de Dworkin, ver o trabalho de Brito Filho (2008) intitulado: Ação afirmativa: primeira análise da medida adotada pela Universidade Federal do Pará para os cursos de graduação. 
9 Nesses casos, a lógica centra-se nas políticas universalistas; a dimensão classe aparece como fator preponderante, sob diferentes perspectivas. Em especial, nos trabalhos de Maggie e Fry (2004) e Magnoli (2003).

10 Ademais, é importantíssimo salientar que as políticas de ação afirmativa nos Estados Unidos funcionaram. Os elucidativos resultados colhidos no livro $O$ curso do rio (2004) concluem que foram inúmeros os benéficos das políticas, assim como demonstram, por meio de dados estatísticos e entrevistas, que todos os principais argumentos levantados contra as políticas de ações afirmativas são infundados. Para a análise que Dworkin faz desses resultados, ver, em especial, o cap. 11, da obra $A$ virtude soberana (2005).

\section{REFERÊNCIAS}

BARROZO, Paulo Daflon. A ideia de igualdade e as açóes afirmativas. Lua Nova, Água Branca, SP, n. 63, p.103-141, 2004. Disponível em: <http:// www.scielo.br/pdf/ln/n63/a05n63.pdf>. Acesso em: 12 jun. 2009.

BOWEN, William G.; BOK, Derek. O curso do rio. Rio de Janeiro: Garamond, 2004.

BRITO FILHO, José Cláudio Monteiro. Ações afirmativas: fundamentos e critérios para sua utilização. Revista do Tribunal de Justiça do Estado do Pará, Belém, v. 50, n. 98, p. 7-16, 2006.

DUARTE, Evandro C. Piza (Coord.). Cotas raciais no Ensino Superior. Curitiba: Juruá, 2008.

DWORKIN, Ronald. O império do direito. São Paulo: Martins Fontes, 1999.

. Uma questão de princípio. São Paulo: Martins Fontes, 2000. . Levando os direitos a sério. São Paulo: Martins Fontes, 2002a.

DWORKIN, Ronald. Sovereign virtue revisited. Ethics, Chicago, n.113, p.108-117, oct. 2002 b.

- A virtude soberana: teoria e prática da igualdade. São Paulo:

Martins Fontes, 2005. 
DWORKIN, Ronald. Ação afirmativa: primeira análise da medida adotada pela Universidade Federal do Pará para os cursos de graduação. $A$ Leitura, Belém, v. 1, n. 1, p. 40-48, nov. 2008.

FERRAZ, Octávio Luiz Motta. Justiça distributiva para formigas e cigarras. Novos Estudos: Cebrap, São Paulo, n. 77, p. 243-253, mar. 2007. Disponível em: < http://www.scielo.br/scielo.php?script=sci_arttext\&pi $\mathrm{d}=$ S0101-33002007000100013>. Acesso em: 2 dez. 2009.

GOMES, Joaquim Benedito Barbosa. O debate constitucional sobre as ações afirmativas. In: SANTOS, Renato Emerson dos; LOBATO, Fátima (Org.). Açóes afirmativas. Rio de Janeiro: DP\&A, 2003. p.15-57.

MAGGIE, Yvone; FRY, Peter. A reserva de vagas para negros nas universidades brasileiras. Estudos Avançados, São Paulo, v. 18, n. 50, p. 67-80, jan./abr. 2004.

MAGNOLI, Demétrio. Desiguais perante a lei. Revista Pangea, mar. 2003. Disponível em: <http://www.consciencia.net/2003/07/26/ magnoli.html>. Acesso em: 10 ago. 2009.

TOSI, Giuseppe. A igualdade, hoje. In: BITTAR, Eduardo C.B.; TOSI, Giuseppe (Org.). Democracia e educação em direitos humanos numa época de insegurança. Brasília: SEDH, 2008. p. 65-83.

VITA, Álvaro de. Justiça liberal: argumentos liberais contra o neoliberalismo. Rio de Janeiro: Paz e Terra, 1993.

ZICCARELLI PANDOLFI, Sandro. As cotas raciais para o acesso à universidade e o princípio da igualdade na C. F. de 1988. Anuario de Derecho Constitucional Latinoamericano, Montevideo, v. 2, año 13, p. 607636, 2000. 


\section{Affirmative action in the United States: an analysis from the perspective of the equality theory of Ronald Dworkin}

\section{Abstract}

Ronald Dworkin's equality theory is based on the premise of equality of resources, as a facet of distributive justice, and is understood to be compatible with a fraternal and liberal society, based on a political principle of equal consideration for all its members. In this sense, the article looks at some of the decisions of the U.S. Supreme Court from the perspective of Dworkin's theory, and offers some brief commentaries about the most recent decisions of that court concerning affirmative action policies. Finally, some considerations are presented about a possible application of Dworkin's theory of liberal equality in Brazil.

Key words: Dworkin, Ronald. Higher education. Equality.
La experiencia norteamericana de las acciones afirmativas: una análisis a la luz de la teoría de la igualdad de Ronald Dworkin

\section{Resumen}

La teoría de la igualdad de Ronald Dworkin está basada en la premisa de la igualdad de recursos, como un faceta de la justicia, compatible con un sociedad liberal fraterna, apoyada en un principio político de la igual consideración de todos sus miembros. En ese sentido, el artículo interpreta algunas decisiones de la suprema Corte de Estados Unidos (USA) a partir de la teoría de Dworkin, como así también realiza breves comentarios sobre las más recientes decisiones de ese Tribunal sobre las políticas de acciones afirmativas. Finalmente, realizamos algunas consideraciones sobre una posible aplicación de la teoría de la igualdad liberal de Dworkin en nuestro país.

Palabras clave: Ronald Dworkin. Educación Superior. Igualdad.

\section{Wilma de Nazaré Baía Coelho}

E-mail:wilmacoelho@yahoo.com.br

Recebido em: 8/1/2010

Aprovado em: 31/3/2010 